\title{
NOTAS SOBRE OS ANGLICISMOS QUEIROSIANOS *
}

\author{
John Austin Kerr Jr. **
}

\section{Introduçāo}

Um dos mais notáveis aspectos da produção literária e outros escritos de José Maria de Eça de Queirós é o tom cosmopolita de scus livros. Em seus trabalhos, nāo somente fez menção a muitos lugares e acontecimentos alheios a Portugal, mas também injetou neles milhares de palavras, frases, sentenças e até mesmo formas mais longas, estrangeiras. Muitos de seus persoragens, assim como o próprio autor na correspondência, empregaram empréstimos espanhóis, italianos, latinos, alemães, franceses, árabes ou ingleses. Por fazê-lo, considero que Eça avivou a narrativa e alargou os horizontes culturais e intelectuais de suas obras (e possivelmente também os do leitor).

No entanto, tal opinião, de maneira nenhuma, é a única existente quando se trata de introduçāo de palavras estrangeiras - estrangeirlsmos - no português, mesmo que tenha sido feita por um escritor importante.

Vasco Botelho de Amaral, por exemplo, censura violentamente a "corrupçāo" que estas palavras causam na lingua portuguesa:

"Para entregarmos a roupa, é indispensável a apresentação deste ticket".

Comentário do meu correspondente:

"Pasmei e, de-certo, o Sr. Prof. Amaral pasmará. Considero de grave atentado contra a língua portuguesa o emprego daquela palavra estrangeira para a qual existem tantas correspondentes em português. Para cúmulo, reparando bem, ticket nem sequer significa o que elas pretendem (sic)". nada.

Apenas digo ao Sr. dr. Carlos Vieira: eu já não pasmo de

- Traduzido do inglés por Terumi Koto. Auxiliar de Ensino de Ĺngua Espanhola no Departamento de Letras Estrangeiras Modernas da Universidade Federal do Paraná.

** John Austin Kerr, Jr. é Mestrz em Educaçāo pela Cornell University (Ithaca, New York) com a tese Various Aspects of the Language Laboratory as it Exists Today (1961) e Mestre na área de Estudos Iberoamericanos pela Universidade de Wisconsin (Madison, Wisconsin) em 1965. Ph. D. por esta Universidade 1970), sus tese, Aspects of Time, Place and Thematic Content in the Prose Fiction of Jose Rodrigues Miguéis as Indication of the Artist's Weltansicht foi elaborada sob orientação do Prof. Jorge de Sena. Tem trabalhos publicados em Littera (Rio de Janeiro), Romanische Forschungen (Colonia, Alemanha) e Arquivos (Curitiba). Atualmente, leciona Lingua Portuguesa. Língua Espanhola e Literatura Luso-Brasileira na Universidade de Northern, Illinois, Estados Unidos. 
Mas aqui lembro à Casa Ramiro Leão que, já que pōe ticket nos bilhetes ou nos talōes. devia mudar o título para Ramiro Lion e passar a loja ali para London, Great Britain ou England. 1

Poucas páginas adiante. Botelho de Amaral coloca o problema ainda mais asperamente, finalizando com uma nota quase histérica:

Talvez ocorra algum sofista que a corrupção é inherente à linguagem humana, por isso mesmo que de coisa humana se trata. Mas o vício, a doença, o crime, a acçāo má, a mentira, o roubo, a desonra, enfim todos os males do mundo não devem ser combatidos? Não se providencia opondo a virtude ao vício, a medicina ou a higiene à enfermidade, o castigo ao crime, a moral à vileza das aç̧ões. a verdade à mentira; não se opōe o bem ao mal?... Quanto ao Idioma posso afirmar, e tenho-o provado e estou as ordens de quem quer que seja para contirmar - A CORRUPCAO CONTINUA. 2

De modo algum Botelho de Amaral é o único a defender esta opinião ou lima similar sobre os cmpréstimos. Por exemplo. Rodrigo de Sá Nogueira inclina-se a concordar, e até mesmo chega à singular conclusão de que, em vista do grande número de empréstimos em português, nāo há verdadeiro espírito nacional:

Nada há que mais me custe que tratar de estrangeirismo: é trabalho absolutamente inútil. e o tempo nāo me sobeja a ponto de poder entreter-me a construir castelos de cartas, que momentos depois cacm com um sopro do indiferentismo nacional...

A introdução de estrangcirismos na nossa língua é questão regulamentada, embora tacitamente: cla dá-se com a mesma regularidade e devido às mesmas causas com que se dá a introdução das modas.

Em presença deste facto chego a convencer-me de que os portugueses ou não têm o verdadeiro conceito de nacionalismo...

Se nāo, como explicar a passividade com que assistimos diariamente à invasão caudalosa de estrangeirismos na nossa língua? 3

Jaime de Magalhāes Lima dá mostras de uma atitude mais calma em relaçāo ao problema, mas prefere obras literárias que lhe pareçam ser mais genuinamente portuguesas. Elc cita Antero de Quental e Eça de Queirós. por exemplo, no seguinte extrato:

Tenho a apreensão de que um dos motivos da accessibilidade obras de Antero de Quental e da perdurabilidade da sua influência, embora se mantenha em clevaçōes religiosas e filosóficas que o vulgo nem sempre alcança, será que Antẹo, muito espontanea-

1 BOTELHO DE AMARAL, Vasco. Mistérios e maravilhas da lingus portuguesa. Porto, Simōes Lopes, 1949. Infelizmente para a discussāo de Botelho de Amaral. a palavra "ticket" poderia ser usada aqui, como "laundry-ticket".

2 Ibid.. p. 503.

3 SA NOGUEIRA, Rodrigo de. Questōes de linguagem. Lisbo8. A. M. Teizeirp 1934. V. $1, p .173-4$. 
mente, por inclinação natural e sem estudo, como ele confessou, escreveu sempre em português legitimo, cantou com a nossa voz... No que o gênio de Antero - convém notar a divergência, que é elucidativa - se apartará do gênio de alguns dos seus contemporäneos e amigos mais ilustres.

Eça de Queiroz, por exemplo, nas obras de pura arte dos seus primeiros periodos, não raro inovou, afastando-se frequientemente do compasso pátrio, até que afinal, num regresso de filho pródigo reagindo por amor, professou na genuinidade nativa. do que $A$ Cldade e as Serras teriam sido, por muitos títulos, qual deles o melhor e o mais nobre, um sinal eloquiente. 0 adejar de conversāo, o renascimento no ventre materno.4

João Ribeiro que também demonstrou uma atitude mais liberal, parafraseou Américo Castro sobre Spitzer num comentário moderado sobre o problema do nacionalismo vs. empréstimos culturais:

Don Américo Castro faz notar a atitude do romancista Leo Spitzer, recordando as palavras do professor de Marburgo:

"Declaro-me partidário do patriotismo e do atento cultivo da língua alemā. porém não da patriotite lingüística dos que querem tudo germanizar".

Essa deve ser a atitude imparcial do filólogo. 5

Finalmente, o gramático brasileiro, Mário R. Martins, é um exemplo dos que acertadamente insistem numa aproximação racional à questão, não importa que língua possa estar envolvida:

Parece-nos pueril a ojeriza que votam alguns homens de letras no Brasil e em Portugal, aos estrangeiros indiscriminadamente. Povos cultos, como o francês e o inglês, hospedam nos seus léxicos grande número de palavras forasteiras e ninguém, até hoje, se lembrou de expulsá-las, substituindo-as por outras de aspecto rebarbativo. Fato que se verifica normalmente em todas as línguas vivas. Acresce notar que os neologismos formados, e mal, de elementos latinos e gregos. não deixam. por isso, de ser estrangeirismos. São, de fato, helenismos e latinismos. Tão pretensiosos como quaisquer outros, senão mais. 6

4 Magalfans lima, Jaime de. A lingua portuguesa e os seus mistérios. Paris, Aillaud, 1923. p. 52-3.

5 RIBEIRO, João. Curiosidades verbais. Rio de Janelro, Săo José, 1963. p. 100. Na verdade, esta foi também a atitude do lingüista emericano Leonard Bloomfleld. Em seu livro Language (New York, Holt, Rinehart and Winston, 1933) a p. 444, ele afirma que: “... throughout his life, the speaker continues to adopt features from his fellows, and these adoptions... are very copious and come all manner of scurces... The adoption of features which difer from those of the main tradition, is linguistic borrowing. Within the sphere of borrowing, we distinguish between dialect borrowing, where the borrowed features come from within the same speech-area... and cultural borrowing, where the borrowed features come from a different language".

6 MARTINS, Mário R, A evoluģăo da lingua nacional. Rio de Janeiro, Borsol, 1943. p. 246-7. 
Tudo isto nāo quer dizer que criticos portugueses e brasileiros nāo tenham estudado vários tipos de empréstimos. O próprio Botelho de Amaral discutiu o uso das formas francesas por Eça de Queirós e o uso por Almeida Garrett do verbo inglês "to flirt", através de adaptaçōes portguesas: to flirt $>$ flirtar $>$ flartar 7 Alérn dessas, Fernando V. Peixoto da Fonseca fez uma lista de algumas formas levadas do inglès para o português, entre elas: bobina, bombardo, bote, breque cheque, clube, drainagem. futebol, grogue, humorista, Júrl, pudim, rosbife, rufo, rum, sanduiche, túnel, turfe, turismo, vagão, xelim. Este autor acrescentou um comentário: “. . os anglicismos vieram diretamente para o português, ou através do francês, como bebê, rosbife e contradança". 8 Além desse estudo, Cândido de Figueiredo publicou um trabalho de dois volumes contendo centenas de empréstimos, enquanto que R.F. Mansur Gućrios recentemente discutiu a história dos empréstimos italianos introduzidos na língua portuguesa. 9

Finalmente, observando a atitude de um dos mais moderados sobre o assunto. Manuel da Paiva Bóleo estuda a situaçāo, e com cuidado especial us empréstimos no português moderno, e resume-a desta forma:

De uma maneira geral pode afirmar-se que a influência francesa, na época atual, embora continue a ser grande, é muito menor que noutros períodos da língua, por ex., no século XIX.

A seguir, por ordem de importância, ao elemento francês, vem o inglês, que se encontra, principalmente, na linguagem desportiva e culinária. Também aqui houve alguns termos que passaram à fala corrente e popular, como esplche (speech, :discurso elogioso" sic, chumaco ("shocmaker"), "sapateiro remendão" sic, móni (money), butes (boots). bife, rosbife, lanche, pudim, etc., para nāo falar de nomes de jogos e desportos. 10

\section{Os Graficos}

Voltando ao assunto sobre Eça de Queirós e seu uso de anglicismos, verifica-se que um grande número deles é claramente visível na Edição Completa da produçāo deste autor, publicada pelo Lello, pois estão em itálico. Desta forma, são evidentes os empréstimos ingleses que Eça quis enfatizaı mais. Além disso, eles constituem uma amostra facilmente verificável (com paciência) deste tipo particular de estrangeirismo.

7 BOTELHO DE AMARAL, Vasco. Meditações criticas sobre a língua portuguesa. Lísboa, Ed. Gams, 1945. p. 184.

8 PEIXOTO DA FONSECA. Fernando V. Noçōes da história de língua portu. guesa. Lisboa, Clássica, 1959 . p. 110.

9 FIGUEIREDO, Cándido de. Os estrangeirismos, Lisboa, Clássica, 1923-28. 2 v. MANSUR GUERIOS, R. F. Os empréstimos italianos da lingua partuguesa. Arquivos do Centro de Estudos Portugueses, Curitiba, 2(1):5-10, jan./fun. 1973.

10 PAIVA BOLEO, Manuel de. Introduçio ao estudo ds filologia portuguesa. Lisbor, Revista de Portugal, 1946, p. 38. Notar, no entanto, as definiçōes estranhamente limitadas de "speech", o que em áreas de fala inglesa nāo é exatamente só "elogioso", e de "shoemaker", o qual nāo significa necessariamente um mero consertador de sapatos. Estes podem ser, portanto, dois exemplos de mudança de significado ao serem os empréstimos adotados na lingua portuguesa. 
Por essa razão, proponho fazer uma lista de resultados do exame da Ed:ção Completa dos trabalhos de Eça de Queirós da casa editorial Lello no gráfico de palavras que segue, na esperança de que se possa chegar a algumas conclusōes, observando seu uso pelo homem que foi certamente um dos mais importantes escritores de Portugal (especialmente na prosa de ficcão) do século dezenove, se não o mais notável. Primeiramente, no entanto, alguns comentários sobre as normas:

A. O termo "anglicismo" inclui tudo que pareça ser Inglês, tanto os vocábulos representados na escrita no Inglês padrão (num gráfico separado) como os que tenham sido ortograficamente adaptados ao português, e o que aparece em itálico na edição de Lello. (Vocábulos estrangeiros como os nomes do cabeçalho na correspondência do autor nāo foram considerados). Estes gráficos são rotulados como "Gráfico I", e "Gráfico II".

B. Estes vocábulos estão apresentados em ordem alfabética para facilitar a referência.

C. As obras consultadas na busca dos empréstimos ingleses estão enumeradas ao lado no topo das folhas, na ordem em que Lello enumerou-as, principalmente por causa da dificuldade em estabelecer uma lista cronologica, a menos que algumas obras, como Correspondêncla, sejam separadas em vários componentes: um processo que tornaria de difícil manuseio os gráficos.

D. A frequiência com que cada vocábulo aparece em cada obra é demonstrada por um número que aparece no lugar respectivo na linha abaixo da do título da obra. Estas linhas ocupam toda a extensāo do gráfico.

E. Os empréstimos em cada obra sāo subtotalizados no final de cada página do gráfico.

F. O número total de vezes que cada vocábulo aparece encontra-se na coluna perto do lado direito das várias páginas do gráfico principal.

G. A direita de (F), será encontrado o número de obras, por volume, em que cada uma das formas aparece.

H. A direita de (G), será encontrada uma indicaçāo da parte do discurso deste vocábulo particular, quando apropriado.

I. Finalmente, encontra-se uma coluna miscelânea "Comentários", para uso em alguns casos.

J. Os totais encontram-se na última página do Gráfico I e no final dos Gráficos II e III.

K. Um asterisco $\left(^{\star}\right)$ ao lado do anglicismo indica que este consta também na lista de Os Estrangelrismos de Candido de Figueiredo, 2 vols, Livraria Clássica Editora, Lisboa, 1923 e 1928.

L. Um trabalho de Rider Haggard - King Solomon's Mine - foi incluído por causa da influência exercida por Eça de Queiroz na sua tradução para o português.

Antes de voltar a atençāo às nossas conclusōes sobre os anglicismos nas cbras de Eça de Queirós, reorganizaremos algumas informações acima cita- 
لlas, a saber por data da composiçāo, 11 para mostrar a freqüência dos cmpréstimos (tendo sempre em mente que estamos tratando somente dos vocábulos destacados em itálico). O resultado é como segue:

\section{Gráfico I I I}

Obra

\section{Prosas Bárbaras \\ O Egipto}

Notas Contemporáneas

Correspondêncla

Uma Campanha Alegre

Contos

Cartas de Inglaterra

o Crime do Padre Amaro

o Primo Basílio

A Capital

o Conde de Abranhos

o Mandarim

A Relíquia

A Correspondência de F.M.

Os Malas

Ultimas Páginas

Cartas Inéd. de F. Mendes

Ecos de Paris

As Minas de Salomão

Alves \& Cla.

Cartas Fam. e Bilh. de Paris

A Ilustre Casa de Ramires

A Cidade e as Serras
Data

1866-1870

1869

1869-1898

1870-1899

1871-1872

depois de 1874

1874-1888

1875

1878

1878

1879

1880

1887

1888

1888

1888-1893

1888-1894

1888-1900

1891

1891 (?)

1893-1897

1900

1900
Anglicismos

6

29

53

45

41

11

246

9

13

58

5

10

10

20

262

3

17

15

23

2

20

14

10

\section{Algumas Conclusões}

Total 922

Em primeiro lugar, parece apenas lógico que a tendência de alguns puristas da linguagem em procurar remover a inclusão de palavras e expressōes estrangeiras na língua portuguesa não somente está condenada a fracassar, mas também, em alguns casos. pode levar a comentários que orlam u ridiculo, ou, pior ainda, àqueles que sāo falsos ou mal orientados. Além disso, comentários de natureza quase histérica sāo facilmente notados e des-

11 Estas datas foram tiradas de Joăo Gaspar Simōes. Eça de Queirós (Lisboa, Arcádia, 1961). ou, ande necessário, foram deduzidas da evidēncia interna nas próprias obras. Em alguns casos, são apenas aproximações às datas da composiçăo devido à maneira como o autor revisou seus manuscritos etc... 
contados, enquanto que se poderia suspeitar que a açāo destes puristas sobre os melhores escritores brasileiros e portugueses é nula. Neste pequeno estudo, temos uma indicação, ainda que parcial e evidentemente limitada, da maneira como um grande homem de letras de Portugal - Eça de Queirós - empregou anglicismos quando melhor lhe pareceu.

Em segundo lugar, parece que o uso que Eça faz dos empréstimos ingleses - pelo menos os que estão em itálico nas ediçōes de Lello - foi relativamente pequeno. Dos possiveis milhões de palavras usadas pelo autor ras suas obras, somente 311 eram empréstimos ingleses, empregados como palavras estrangeiras. O autor usou-as no total de 922 vezes nos 25 volumes de prosa que foram cxaminados durante o transcurso deste estudo. Adicionalmente, Eça empregou 16 palavras e frases que tinham sido adaptadas de alguma forma à língua portuguesa. Estas foram apresentadas em itálico, de modo suficientemente interessante, num total de 38 vezes.

Em terceiro lugar, a despeito da conhecida antipatia de Eça por uma parte do mundo falante de Inglês - os Estados Unidos - parece haver uma relação entre a longa estada do autor na Inglaterra (que estava peln menos mais perto da Ëuropa) a o número de anglicismos usados em certas obras. No entanto, esta relaçāo ć apenas uma coisa muito geral, e a frequiência do uso de anglicismos passa despercebida em cada final dos três gráficos. Pare. ce haver uma correlaçāo muito mais concreta entre os assuntos das várias obras, num sentido amplo, e a freqüência dos anglicismos. Quando o autor escreve na Inglaterra, e escreve sobre fatos ingleses, tende a usar mais palavras e expressões inglesas, para descrevê-los. Quando Eça coloca personagens de caráter muito cosmopolita nas suas histórias, a freqüiência do uso cos empréstimos tende a aumentar, em alguns casos, bastante dramaticamente.

As exceçōes a esta tendência são evidentes, naturalmente. $O$ supersofisticado Jacinto, em A Cidade e as Serras, por exemplo, quase não usa palavras ou frases inglesas. Neste caso deve ser lembrado, no entanto, o fato de que este livro foi escrito por um homem que estava quase no fim de sua vida e que estava simbolicamente reintegrando-se na vida portuguesa, contrastando os prazeres gastos na cosmopolita Paris com as amadas imagens de sua terra natal. Assim haveria pouca necessidade de anglicismos em tal obra.

Em quarto lugar, nota-se que a esmagadora maioria dos anglicismos usados são substantivos ou frases nominais de alguma espécie. Assim, o inglês que o autor emprega tende a ser usado para descrever coisas materiais e imateriais. Os modificadores destas palavras tendem a ser em português. Por exemplo, ele não diz algo como, "a green coisa", mas "o whist de todos os dias". Por essa razāo, falando de uma maneira geral, o simbolismo inglês u'sado por Eça é muito simples, envolvendo somente a substituição de um rótulo verbal por um outro. 
Em quinto lugar, torna-se óbvio pelos gráficos que um certo número de vocábulos ingleses nas obras examinadas aparecem $\mathrm{cm}$ forma incorreta. No entanto, raramente são mal empregados. Consequentemente, parece que muitos deles podem ser postos de lado como resultado de erros tipográficos da parte dos publicadores. Entretanto, onde as formas que são estranhas para o ouvido americano sáo singulares, parece possivel que o erro foi (a) ou cometido primeiramente pelo autor, apesar de seu conhecimento do mundo e de suas linguas, ou (b) que elas foram consideradas como diferenças existentes entre o inglês americano e a variante britânica ou como resultado que quase um século de tempo produziu tanto na América como na Grä-Bretanha. Um caso interessante, neste particular, é a palavra "shake-hand", com a significado de "tip". Isto não consta nos dicionários do moderno Inglès que foram consultados. Tampouco aparece no Inglês corrente e mocierno da América. No entanto, aparece num dicionário americano completo; assim sendo, pode representar um caso de preservaçāo de uma forma particular usada na primitiva colônia inglesa, entre pequenos grupos de pessoas do interior da América, enquanto que morreu no primitivo país de origem e nos modernos centros culturais da América. E talvez, o mais estranho de tudo, naturalmente, seja a preservação casual da palavra no munco falante do português.

Em sexto lugar, torna-se óbvio pela leitura de Eça que, a despeito destas dificuldades menores, os anglicismos empregados são efetivos na criação de um certo tom ou ambiente, ou na adiçāo de certos elementos à narrativa. Considerem a diferença entre aguardente e "whiskey", que presumivelmente significa scotch whiskey, depois da tradição européia.

Como ponto seguinte, também pode ser observado pelos gráficos anterores que Eça de Queirós usou muitos empréstimos ingleses que não foram catalogados por Cândido de Figueiredo cerca de trinta a cinquienta anos mais tarde. Se isto se deveu ao desaparecimento desses empréstimos da cena portuguesa neste intervalo. ou à peculiar história da publicação de algumas das obras de Eça, é secundário. O que isto significa é que se deve usar a compilação de Cândido Figueiredo com cuidado, pois ela é evidentemente incompleta. No caso em questão, deve-se lembrar somente de que Os Maias foi publicado algumas décadas antes da publicação de Os Estrangeirismos, e que o primeiro era quase um trabalho desconhecido pelo autor pouco conhecido.

Finalmente, quando se considera que Eça de Queirós empregou tanto os empréstimos franceses, latinos, alemães, espanhóis, árabes, italianos como os ingleses, compreende-se bem a magnitude que um estudo completo sobre o assunto envolveria, como também as limitaçōes destas poucas notas sobre os anglicismos queirosianos. 


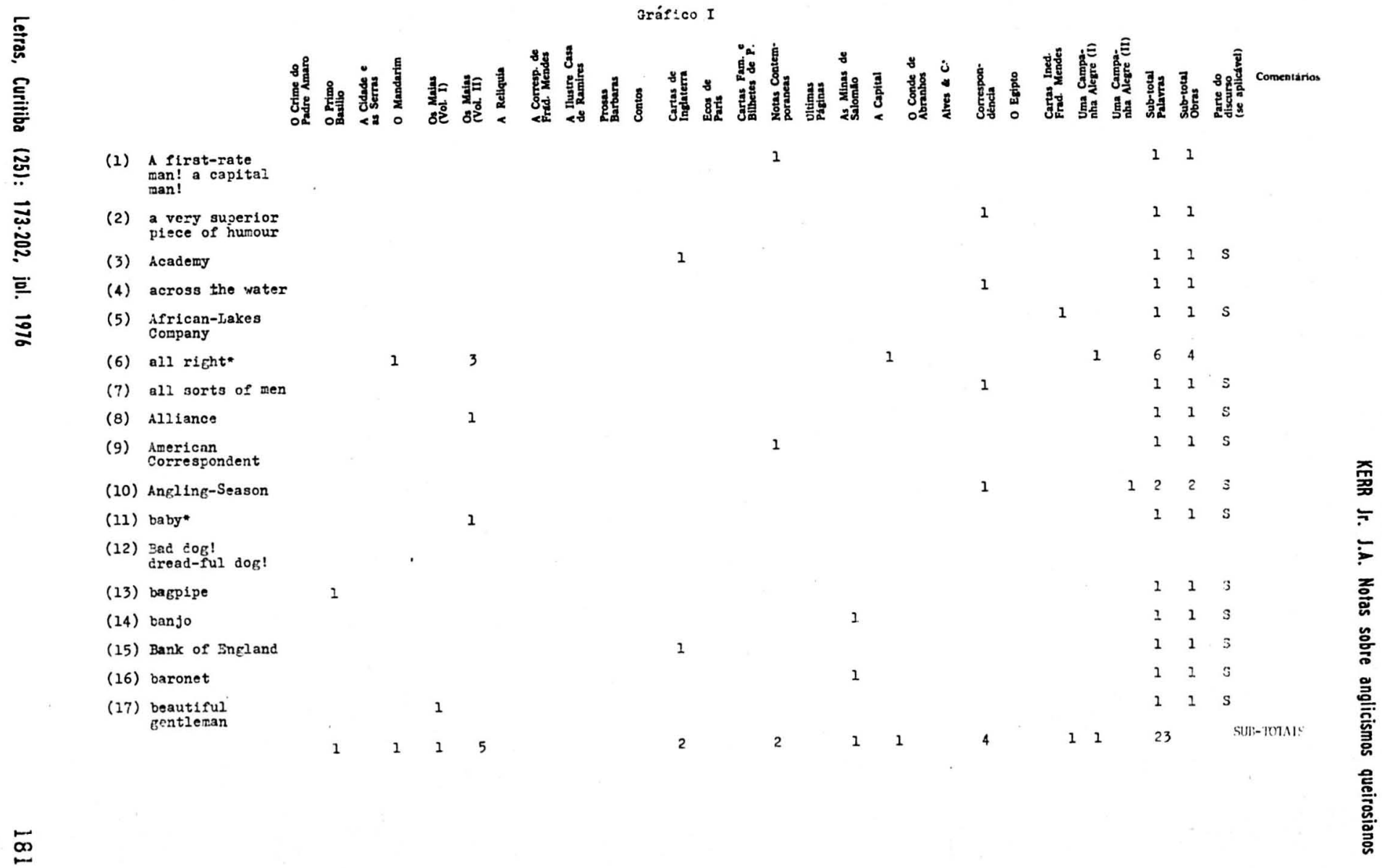


Gráfico I

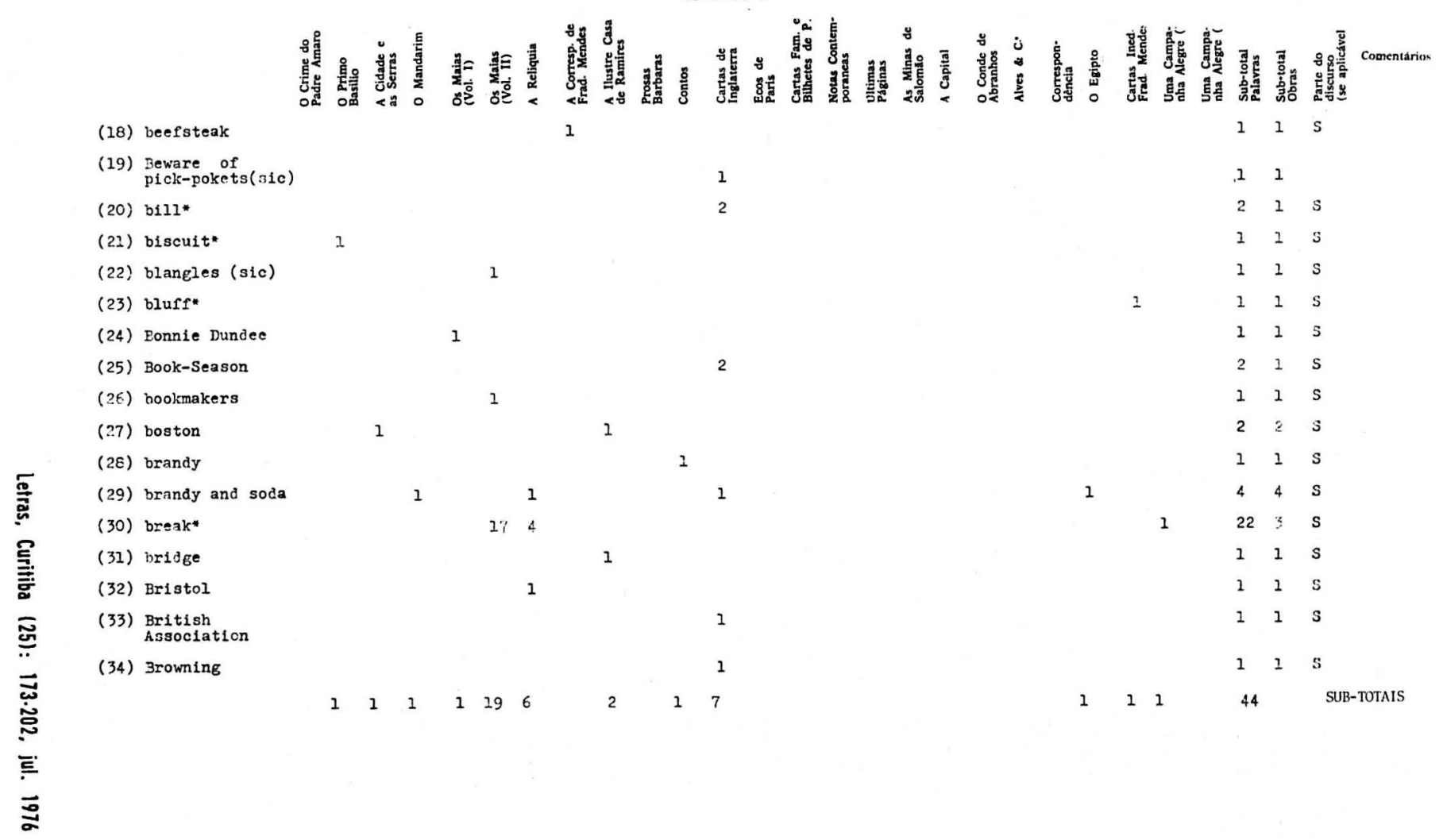


Grifico I

点

(35) bull-cog*

(36) bull-ciogs



1

(37) Burglary-Season

(38) bush

(39) cab

(40) cabs

(41) camps

(42) cant

(43) charge*

(44) Charing-Cross

(45) cheer full
mind (sic)

(46) City

(47) clergiman (sic)

(48) clown*

(49) cluts

(50) Coals! coals!

(51) Congress-Season

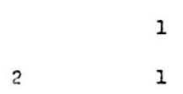

1 
Grífico I

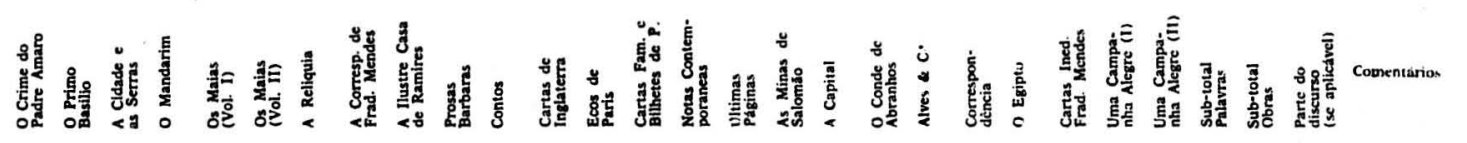

(52) cool1e

(53) coolies*
(como "coolis"-sic)

54) cottage

(55) country of snobs

(56) Covent-Garien

(57) Craft

(58) cricket*

(59) Cricket-Season

(60) Daily News

(61) Daily Telegraph

(62) dandies

(63) dand̄y*

(64) dead-beat

(65) Delly*
(cono "Delhi")

(66) dog-cart*

(67) dog-carts

(68) Dragon's Teeth
115

1

1

1

1

1

114

$1 \quad 14 \quad 12$
15 Gujerati

$\begin{array}{lll}1 & 1 & 5 \\ 2 & 2\end{array}$

735

123

125

428

115

225

325

425

$22 \mathrm{~s}$

$12 s$ Gíria

$1 \quad 1635$

115

$\begin{array}{lllllll}1 & & & & 1 & 1 & 5 \\ 2 & 4 & 1 & 2 & 50 & & \text { SUB-TOTAIS }\end{array}$ 





ârifico I

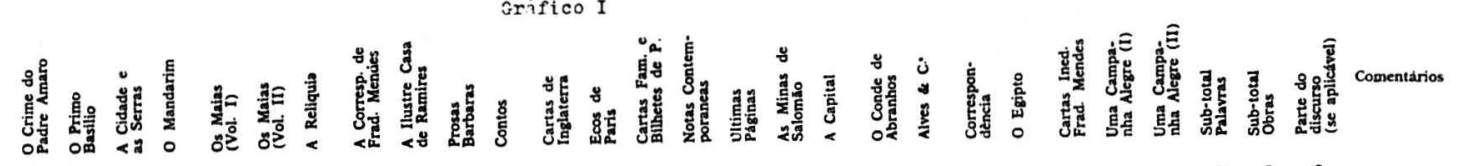

(86) foot-ball* 1

115

(87) Forelgn office

(96) Bentlemen

(97) gin

(98) globetrotters

言

(88) four-in-hand

(89) fox-terrier

(90) fox-terriers

(91) fruit salt

13

(92) General Grant

(93) generous

(94) gentleman *

(95) gentleman-rijer

$1 \quad 15 \quad 4$

(99) God save the queen* (coro"God save the

2



(100) Good bye

(101) Good morning

(102) Good morning, sir.

\section{1}

115

$21 \mathrm{~S}$

1 I S Ilsado como

115 adj.

$42 \mathrm{~s}$

115

115

$40 \quad 12 \quad 5$

115

$\begin{array}{lll}1 & 1 & 3\end{array}$

$\begin{array}{lll}5 & 4 & 5\end{array}$

115

$$
22
$$

21 exci.

11 excl.

22 exci.

67 StB-TTM:1: 


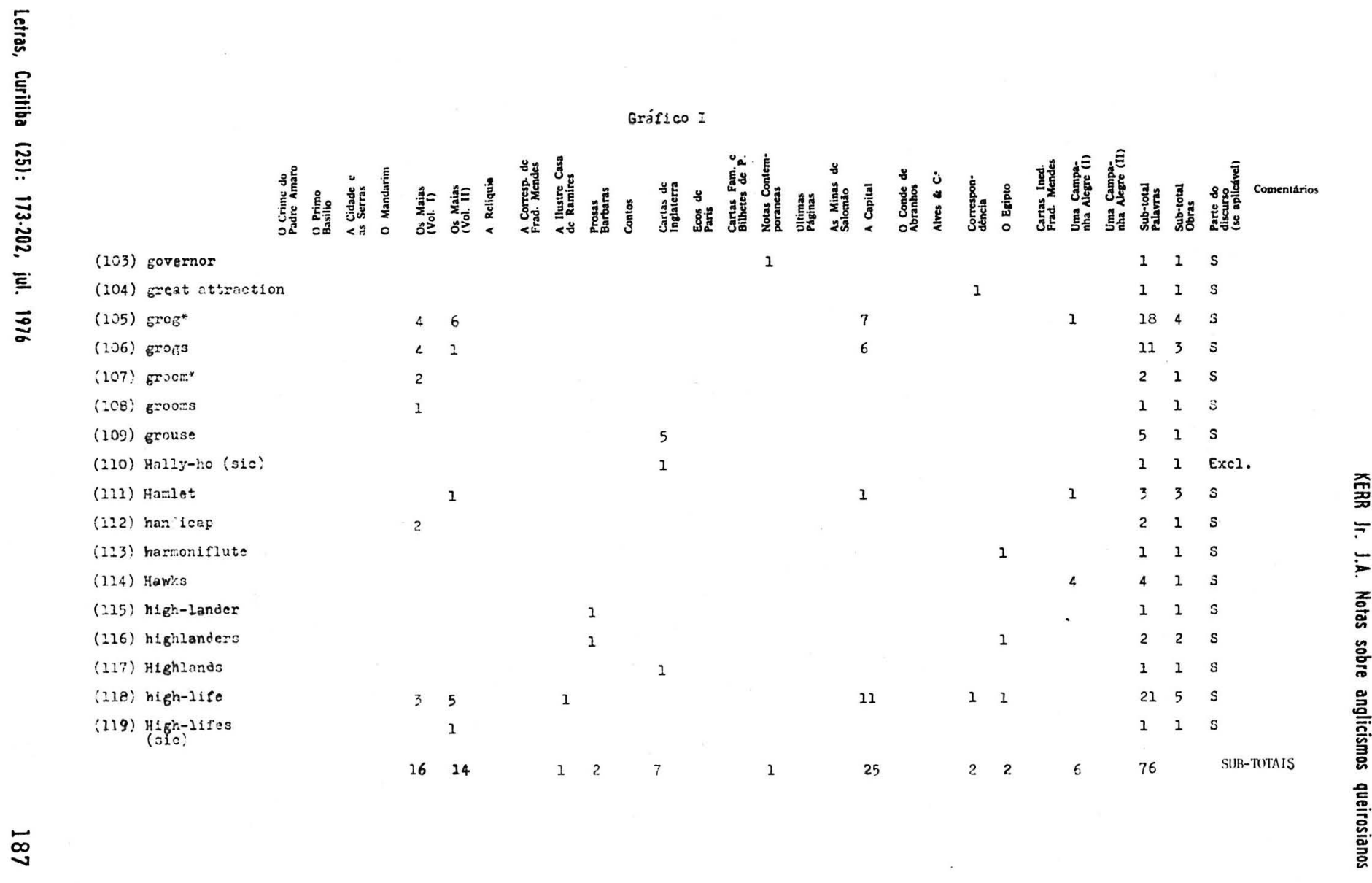




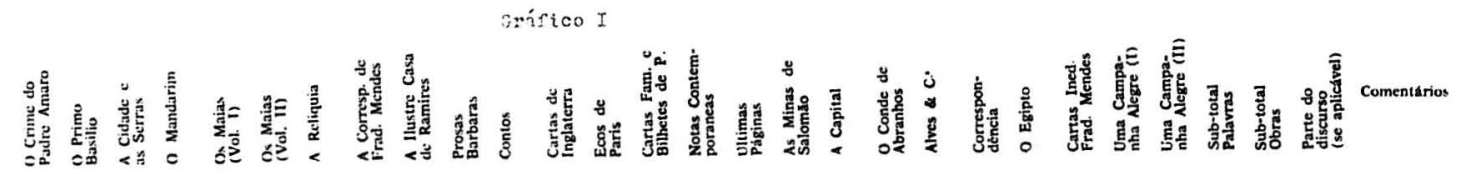

(120) home

(121) Hore-ruless

(122) Horse-garas $_{(s: c)}$

(123) humour

(224) मunt:ng-डoason

(225) hurrah

(125) hurroths

(127) if you piease

(1.28) income-tax

㺃

(129) interrier*

(230) interviews

(131) Intransigeant

(132) iron-works

(i33) Jineo

(134) jockey*

(135) Jockey-club

(236) John
1
1

$$
1
$$

1

1

1

1
1

115

115

1213

$\begin{array}{lll}2 & 2 & \mathrm{~S}\end{array}$

I I 5

32 Intj.

43 Intj.

11

$11 \mathrm{~s}$

215

115

$11 \mathrm{~s}$

115

1

$\begin{array}{llll}2 & 2 & 1 & 5\end{array}$

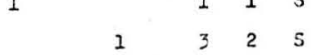

315

15112

$2129.1129 \quad$ SUB-TOTAIS 
Grírico I

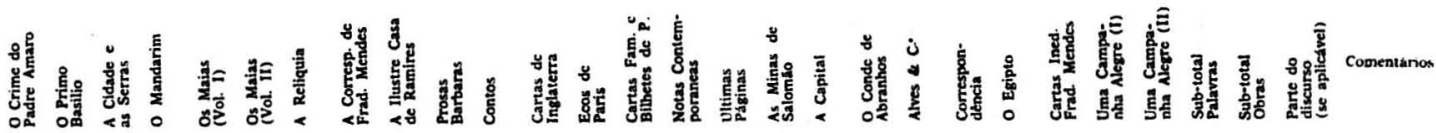

(137) John Bull

(133) John, Snith,
Chariie, "'ilite

(139) Zeepsakes

(140) King Charles

(141) zing Salozon's Hines (sic)

(142) knicker-bokers
(sic)

(143) ladies

(144) ladies and Eentleren

(145) lady

(146) land-1ord

(147) land-loris

(148) Lecture-Season

(149) Iriverpool and IIssissipi Steam Ship Company

(150) lodging

(151) Loksley Hall

(152) London and
Brazilian Bank

(153) London-Season

1

1

1

1

1

1

21
$21 \mathrm{~S}$

$11 \mathrm{~S}$

115

215

13

15

125

$11 \mathrm{~S}$

115

115

115

113

$1 \quad 6 \quad 4 \quad 5$

315

215

115

135

27 SUB-TOTAIS 
Gráfico I



(154) lord*
(155) lords
(156) Lothni

(157) Iunch

(158) Iunchs (sic)

(159) Nacbeth

(160) macfarlane

(161) Machine Politics and Money in Elec

(1E2) mail-coach

옳 (163) makintosh (sic)

总 (164) Kall

E (165) Nanchester

氞 (166) Narble llall

(167) Narc Mrain (sic)

ज़ (168) Marsh

ت. (169) Mary

تै (170) mediums 


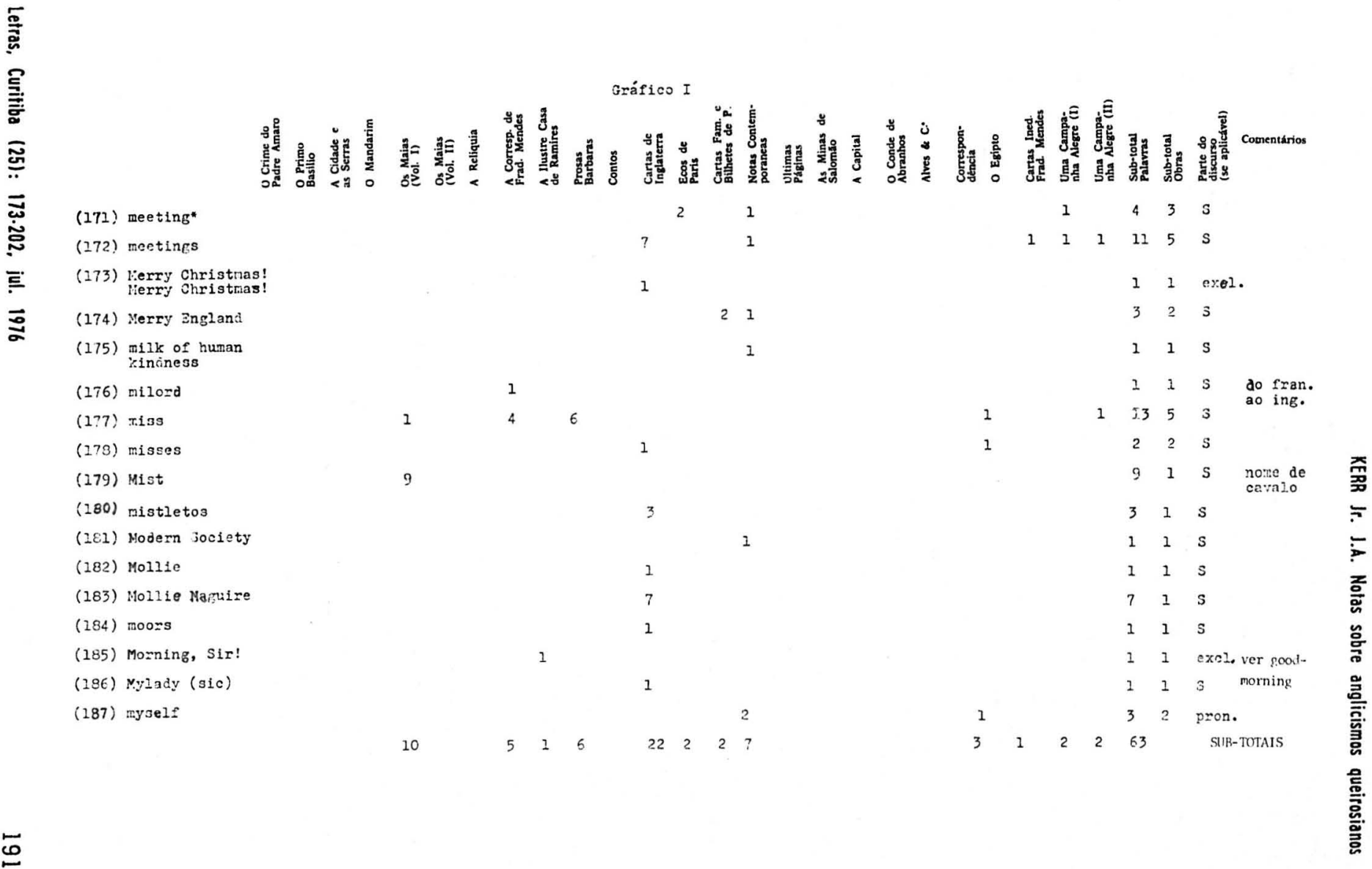


Gráfico I

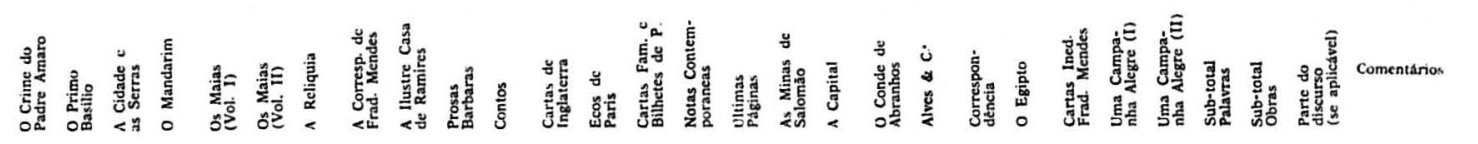

(188) nursery

115

(189) "Oh, ay cousin Oh, my Amy, mine no more on, the creary, dreary moorland! On, the barren,

(190) Oh! Thank you,sir!

(191) Oh yes!

(192) Oh yes, I am very
confortabie! (sic)

(193) Oh yes, sir.

(194) On Tyne



(195) Oxford Street

\begin{abstract}
(196) Pale star
\end{abstract}
(197) Pall Mall

(198) Pall-Mall Gazette

(199) penny

(200) Picliwick

(201) pic-nic*

(202) plaid

(203) plaids 

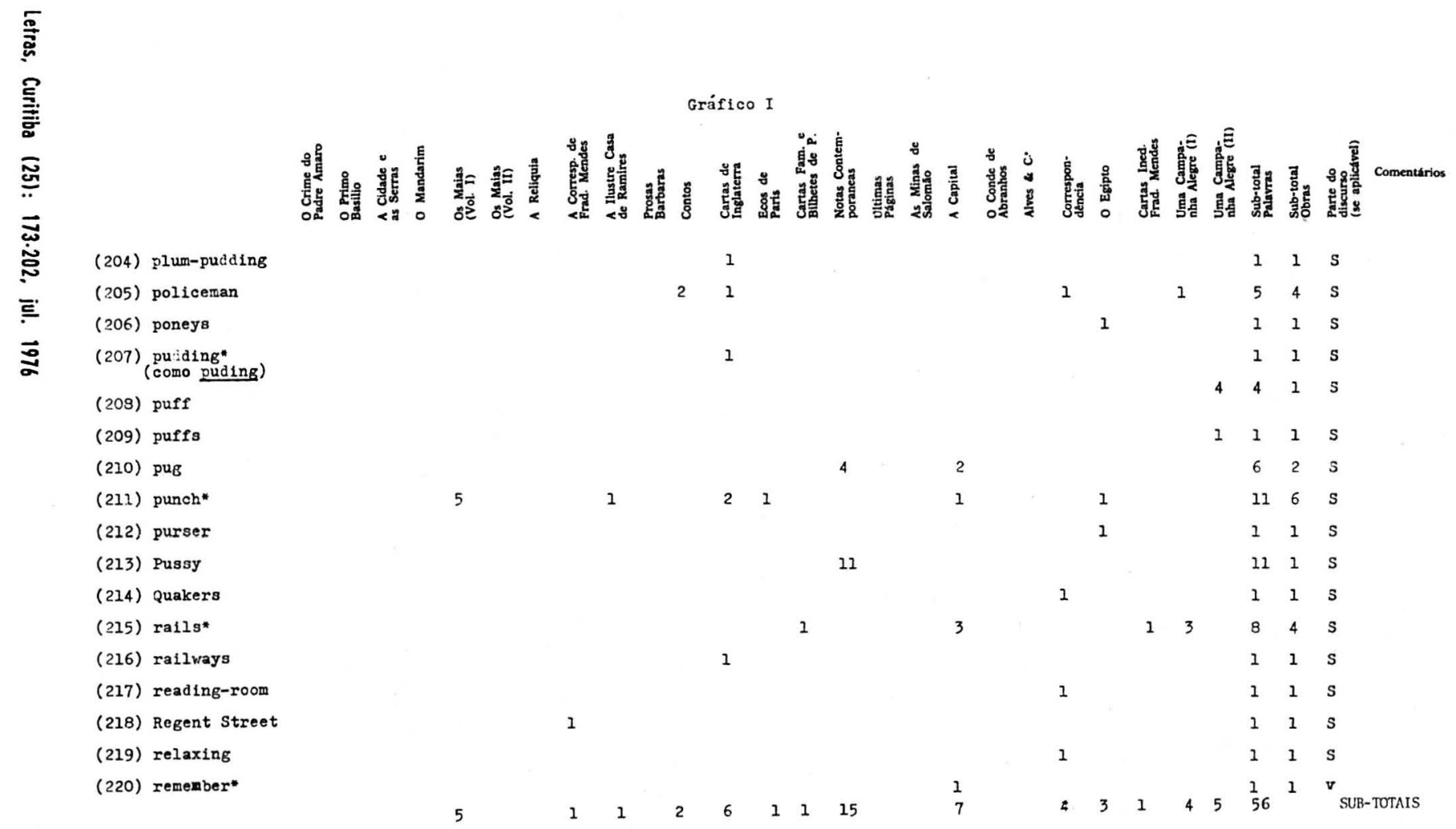
Gráfico I

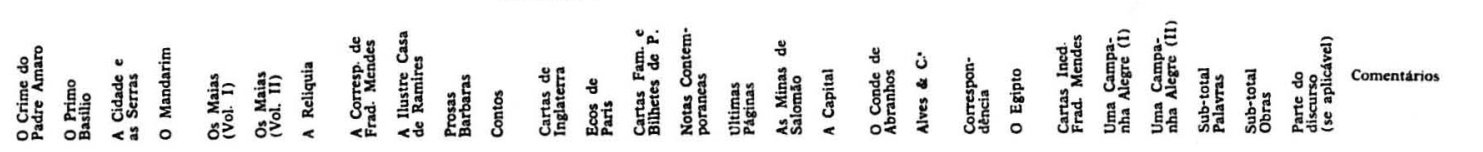

(221) roast-beef*

(222) robber (sic)

(223) robbers (sic)

(224) roughs

(225) Royal llail

(226) Ruby

(227) running

(228) Salvation

(229) sandwich*

急

(230) sandwiches

(231) Saturay

(232) season*

(233) seasons

(234) self- possession

(235) shake-hand*

(236) shake-hands

(237) Shepheard's
Hotel (sic)
1



1

11

1

1

1

1

21

23 
Gráfico I

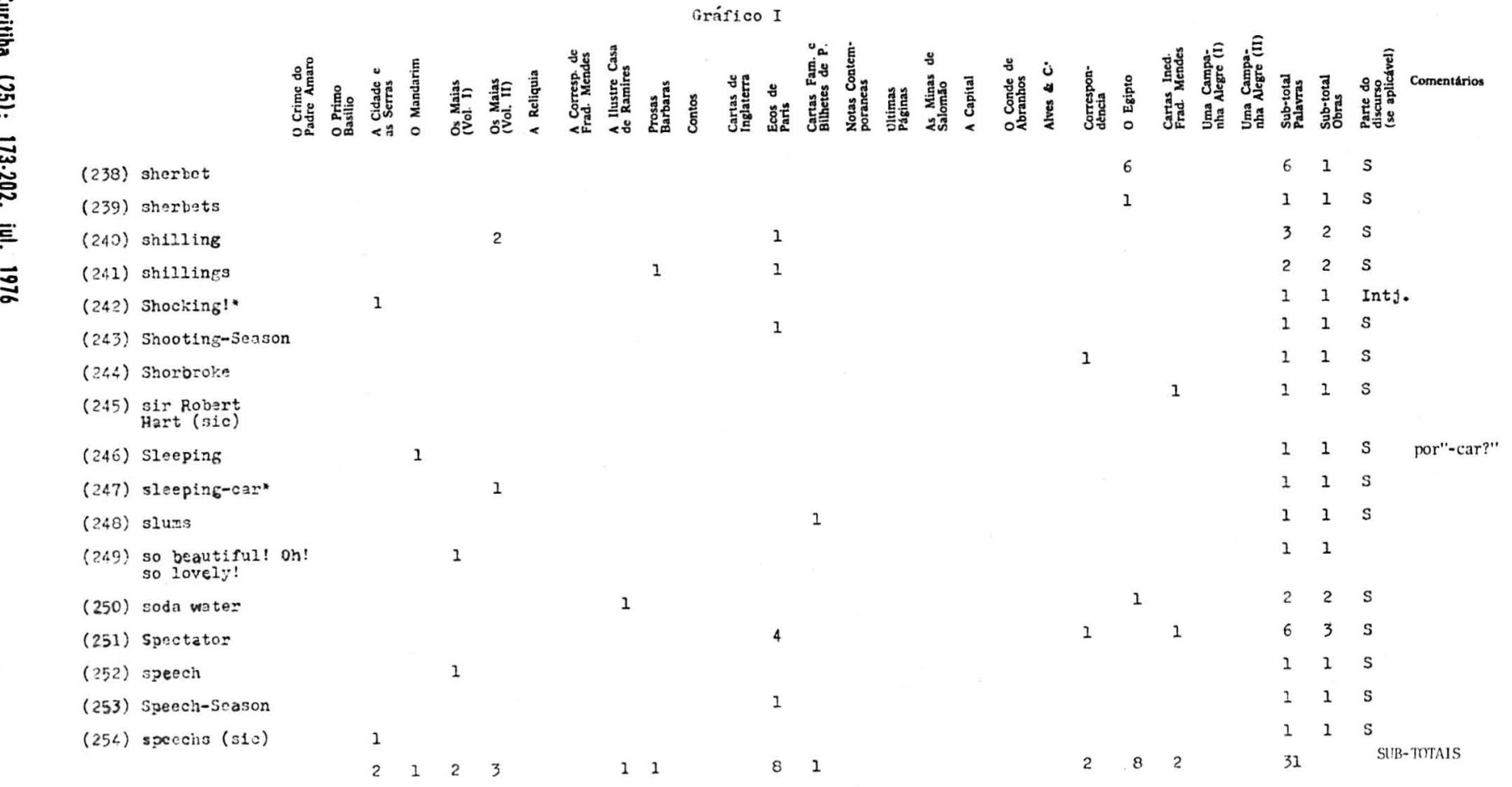


Grifico I
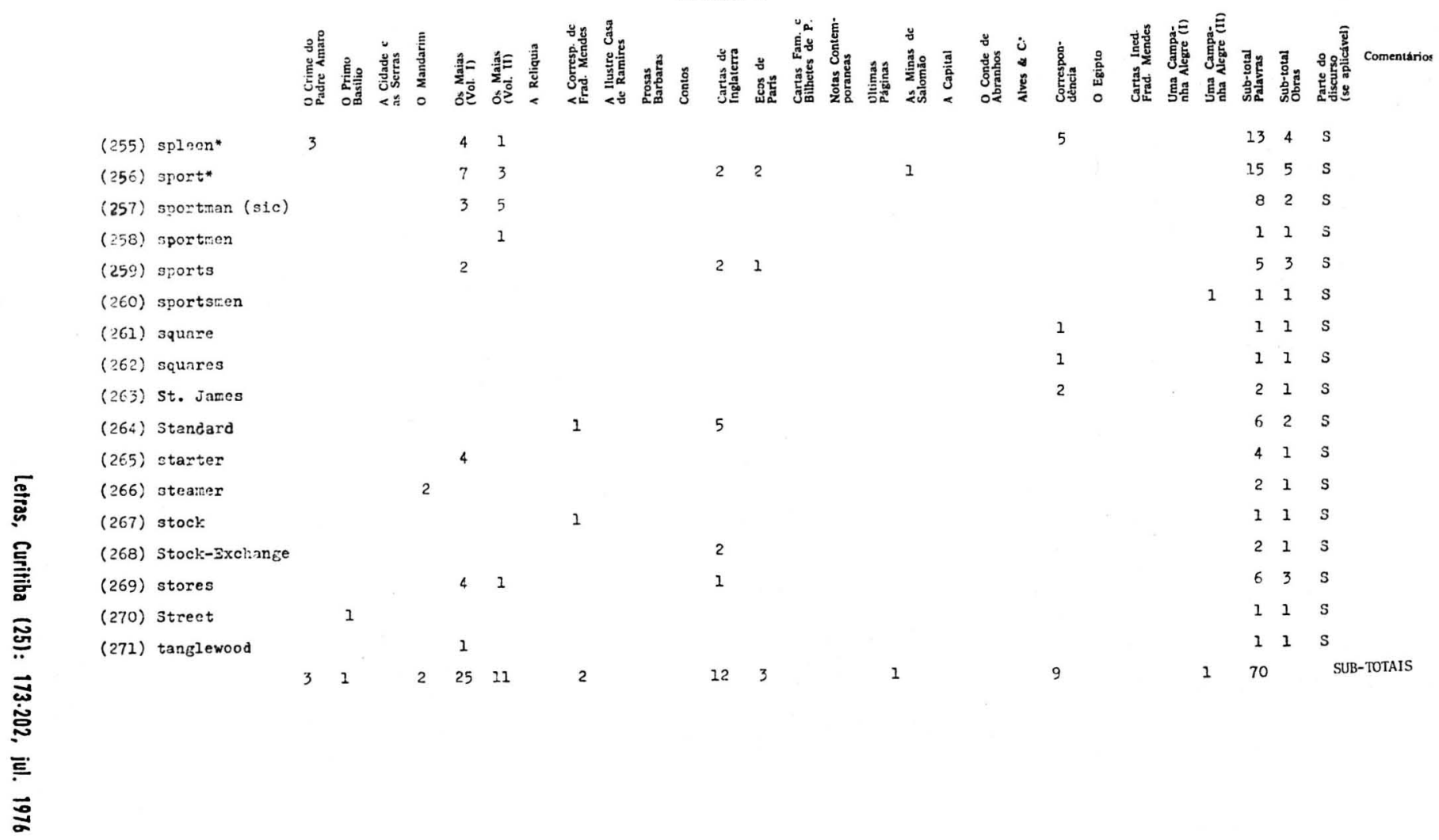
Gráfico I

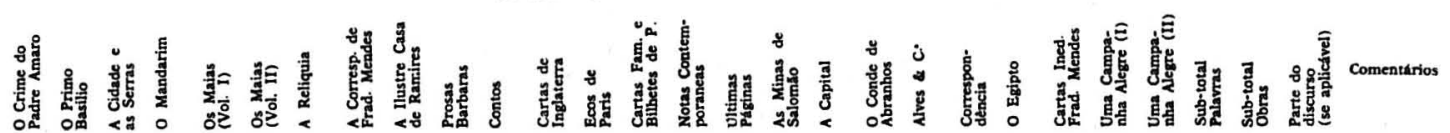

(289) tub

(290) Turf

(291) ulster

(292) United States

Mr. Eça de Queiroz

guese Consul

8, Peare Street

(293) Vivian

(294) Vivian Grey

(295) Water-Closet*

(296) waterproor*

(297) We don't want to

(299) whig

(300) whist*

(301) wholesale laugters (sic)

(302) "ight

(303) $\underset{\text { (sic) }}{\text { (sisky }}$ and soda

(304) Nork-House
$11 \mathrm{~S}$

115

533

11

3

125

2. 15

215

1635

1 fight, sut by Jingo

(298) Westminster
1



1

1

11

$11 \mathrm{~s}$

115

$\begin{array}{lll}27 & 9 & S\end{array}$

115



115

325 
(305) yacht*

(306) Yachting-Season

(307) jachts*

(308) yankee

(309) yankees

(310) yes

(321) Yes, I am the
doctor
5



18
515

115

315

$103 \mathrm{~S}$

$11 \mathrm{~S}$

$22 \mathrm{Adv}$.

11

23

TOTAIS $\begin{array}{llllll}45 & 29 & 17 & 25 & 16 & 922\end{array}$

$\begin{array}{lll}9 & 1 & 9\end{array}$

- relacioredos em Os estrangeirismos de candido de Figueiredo, v.I, 1923 ou v.II, 1928. 
Gráfico II
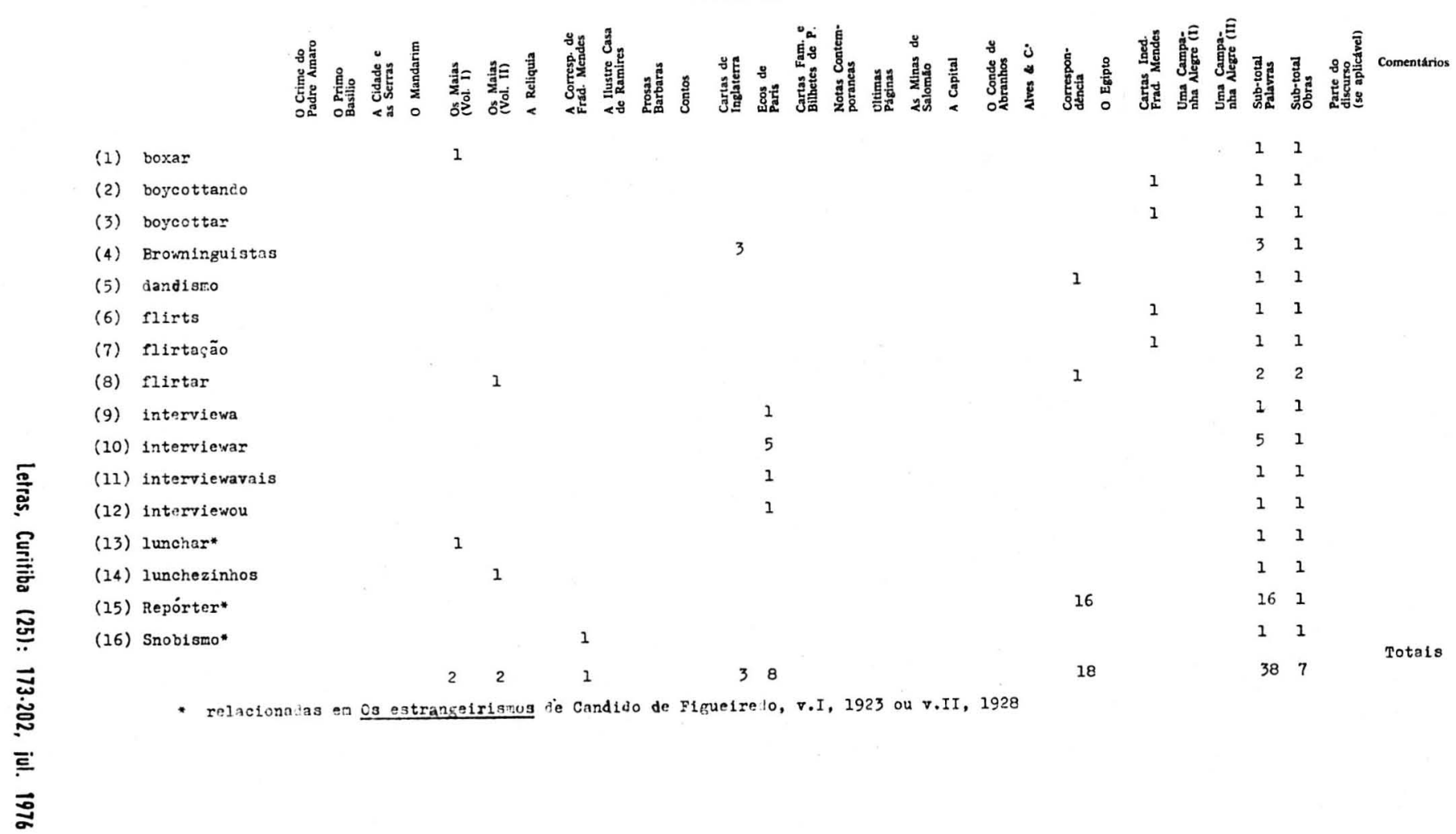

$\begin{array}{llll} & & 1 & 1 \\ & 1 & 1 & 1 \\ & 1 & 1 & 1 \\ & & 3 & 1 \\ & & 1 & 1 \\ & 1 & 1 & 1 \\ & & 1 & 1 \\ & & 2 & 2 \\ & & 1 & 1 \\ & & 5 & 1 \\ & & 1 & 1 \\ & & 1 & 1 \\ & & 1 & 1 \\ & & 1 & 1 \\ & & 16 & 1 \\ & & 1 & 1 \\ & & & 38 \\ & & & \end{array}$


KERR JP. J.A. Notos sobre anglicismos queirosianos

\section{REFERENCIAS BIBLIOGRAFICAS}

BLOOMFIELD, Leonard. Language. New York, Holt, Rinehart and Winston, 1933. $564 \mathrm{p}$.

BOTELHO DE AMARAL Vasco. Meditacöes sobre a língua portuguesa. Lisboa, Ed. Gama, 1945. 328 p. 700 p. Mlstérios e maravilhas da lingua portuguesa. Porto, Simões Lopes, 1943.

EÇA DE QUEIROZ, Jose Maria. Alves \& C.a. 8. ed. Porto, Lello, 1952.

$183 \mathrm{p}$.

Cartas de Inglaterra. Porto, Lello, 1951. $203 \mathrm{p}$.

Cartas familiares e Bilhetes de Paris; 1893-1897. Porto, Lello, s.d. 235 p. Lello, s.d. $257 \mathrm{p}$.

- Lello A cidade as serras. Porto, Lello, s.d. 307 p.

O conde de Abranhos e A catástrofe. Porto, Lello, 1963.230 p.
Contos. Porto, Lello, s.c. 299 p.

Correspondência. Porto, Lello, s.d. 288 p. s.d. 239 p.

A correspondência de Fradique Mendes; memórias e notas. Porto, Lello,

—. O crime do Padre Amaro; cenas da vida devota. Porto, Lello, s.d. 620 p.
Ecos de Paris. Porto, Lello, s.d. 230 p.

o Egipto; notas de viagem. Porto, Lello, s.d. 276 p.

A ilustre casa de lamires Porto, Lello, s.d. $457 \mathrm{p}$.

Os maias; episódios da vida romantica. Porto, Lello, s.d. 2 v.

O mandarim. Porto, Lello, s.d. $162 \mathrm{p}$.

Notas contemporáneas Porto, Lello, s.d. 556 p.

0 primo Basilio. Porto, Lello, s. d. 561 p.

Prosas bárbaras. Porto, Lello, s. d. 291 p.

A relíquia. Porto, Lello, s.d. 349 p.

Ultimas páginas; manuscritos inédttos. Porto, Lello, s.d. 427 p.

- Uma campanha alegre de "As Farpas". Porto, Lello, s.d. 2 v.

FIGUEIREDO, Candido de. Os estrangeirismos. Lisboa, Clḱssica, 1923-28, 2 v.

GASPAR SIMOES, Jō̄o. Eça de Queirós. Lisboa, Arcádia, 1961. 217 p.

HAGGaRD, Rider. As minas de Salomāo. Trad. e ed. de José Maria Eça de Queiroz. Porto, Lello, s.d. 265 p.

Magalhates IIMA. Jaime de. A lingua portuguesa e os seus mistérios. Paris, Allaud, $1923.154 \mathrm{p}$.

MANSUR GUERIOS, R.F. Os empréstimos italianos da língua portuguesa Arquivos do Centro de Estudos Portugueses, Curitibs, 2(1):5-10. jan./jun. 1973.

MARTINS, Mário $R$ : A evolugaão da lingua nacional. Rio de Janeiro, Borsai, 1943. $364 \mathrm{p}$.

THE OXFORD Universal dictionary on historical principles. 3. ed. rev. London, Oxford University Press, 1955. $2515 \mathrm{p}$.

PAIVA BOLEO, Manuel de. Introdução ao estudo da filologia portuguesa. Lisboa, Revista de Portugal, 1946. $150 \mathrm{p}$.

PEIXOTO DA FONSECA, Fernando $\mathrm{V}$. Noçōes de história da língua portuguesa. Lisboa, Clássica, 1959. $177 \mathrm{p}$.

RIBEIRO, João. Curiosidades verbais. Rio de Janeiro, São José, 1963. 244 p.

SA NOGUEIRA, Rodrigo de. Questōes de linguagem. Lisboa, A. M. Teixeira, 1934. $3 \mathrm{r}$.

THE SHORTER Oxford English dictionary on historical principles. 3 ed. London, Oxford University Press, 1952. 2 v.

WEBSTER'S Third new international dictionary of the English language. Springfield, Mass., G. \& C. Merriam, 1961. 2662 p. 
KERR Jr. J.A. Notas sobre anglicismos queirosianos

\section{Resumo}

O presente artigo pretende mostrar o valor dos anglicismos que Eça de Queirós introduziu nas suas obras, enriquecendo de maneira decisiva a língua portuguesa. Apesar de tratar-se de uma contribuição valiosa, muitos estudiosos criticaram-no violentamente pela corrupção linguística. Esta atitude foi sendo pouco a pouco substituída por uma compreensāo maior sobre empréstimos e, consequentemente, sobre os anglicismos queirosianos.

Os gráficos demonstram objetivamente a frequiência e a variedade destes anglicismos e permitem tirar algumas conclusōes: a) a tentativa de alguns puristas da linguagem em remover empréstimos resulta nula, visto que estes acabam incorporando-se à língua em questão; b) o uso que Eça fez dos anglicismos ć relativamente limitado, contando-se apenas 311 empréstimos deste tipo; c) há uma estreita relação entre o assunto das obras e a fïcqüência dos anglicismos; d) a grande maioria dos anglicismos usados são substantivos ou frases nominais; e) alguns vocábulos ingleses estão cm forma incorreta. mas raramente mal empregados; f) é óbvio que os anglicismos dão um matiz especial a sua narrativa; g) muitos empréstimos ingleses usados por Eça nāo foram arrolados por Cândido de Figueiredo e é, portanto, s:conselhável um certo cuidado ao consultar o seu trabalho.

Considerando que Eça de Queirós nāo somente usou empréstimos ingleses como também franceses, italianos, latinos, alemães, espanhóis e árabes, compreende-se o valor de um estudo completo sobre o assunto.

\section{Summary}

The purpose of this article is to show the value of the anglicisms that Eça de Queirós introduced in his works, enriching the Portuguese language considerably. Although it is an important contribution to the language, many experts criticized him violently for such linguistic corruption. This attitude has fradually been replaced by a greater comprehension of the loan-forms and, therefore, about queirozian anglicisms.

The charts clearly. show the frequency and the variety of these anglicisms and give us some conclusions; a) the effort of some linguistic purists to remove loan-forms is nullified, because they eventually get into the language anyway; b) Eça docs not make use of many anglicisms; there are only 311 loan-forms of this kind; c) there is a strict correlation between the subject of his books and the frequency of the anglicisms; d) the majority of the anglicisms used by Eça are nouns or nominative phrases; c) some English items are badly written but they are rarely wrongly used; $f$ ) it is undeniable that the anglicisms used by Eça give a cosmopolitan colouring to his works; g) many loanforms used by $E_{c ̧ a}$ are not listed in the two-volume book by Candido de Figueiredo and therefore, it is necessary to be careful when consulting this work.

As Eça de Queirós used not only English loans, but also French, Italian, Latin. German. Spanish and Arabic ons, we can appreciate the great importante of a complete study of this subject. 